\section{Lower GI tract - clinical}

OXI/1 356

SEGMENTAL COLONIC MOTILITY WITH AND WITHOUT CISAPRDE UNDER FED AND FASTING CONDITIONS. C.I. Wider-Smith U. Scheurer, S. Hurlimann, A. Schmassman, J. GroB, F. Halter and H.S. Merki. Gastrointertinal Unit, Inselspital, University of Berne, Switzerland.

Transport characteristics and modulation in response to stimuli varies between colonic segments. To assess segmental motility patterns in the transverse, descending and sigmoid colon under fasting and fed conditions, colonic motility was measured for $4 \mathrm{~h}$ in 8 healthy volunteers (ages 21-28), using piezoresistive pressure transducers and a 6-channel datalogger (Gastroscan $R$ 6020, MIC, Switzerland). Three pairs of transducers were spaced $25 \mathrm{~cm}$ apart. Manometry catheters were positioned at colonoscopy, after preparation with only a small enema. Subjects were given placebo or cisapride $10 \mathrm{mg}$ tds for 3 days before manometry in a cross-over design. Meals and activities were standardised. For preliminary analysis, the area-under-the-curve (AUC) of the matility-indices of the pressure recordings ( $\mathrm{mmH}$ ) were compared between a $1 \mathrm{~h}$ fasting and $1 \mathrm{~h}$ fed period, with and without cisapride.

Results: group median AUC (range) of the motility indices with and without cisapride in the fasting and fed periods are shown:

\begin{tabular}{|c|c|c|c|c|}
\hline TRANSVER & SE COLON & DESCENDING COLON & SIGMOID C & OLON \\
\hline PLACEBO & CISAPRIDE & PLACEBO CISAPRIDE & PLACEBO & CISAPRIDE \\
\hline fasting & & & & \\
\hline $0.55(.46-.78)$ & $0.66(.45-1.1)$ & $0.44(.24-8) \quad 0.74(.38-1.9)$ & $0.43(.13-.74)$ & $0.48(.27-1.7)$ \\
\hline fed & & & & \\
\hline $1.03(.77-1.5)$ & $1.11(.78-1.6)$ & $0.88(.54-2.0) 1.21(.85-2.8)$ & $0.61(.34-1.8)$ & $0.79(.18-3.0)$ \\
\hline fasting us fed & & & & \\
\hline$p<0.001$ & $p<0.01$ & $p<0.01$ & $p<0.05$ & h.s. \\
\hline placebo vs ci & sapride & & & \\
\hline all n.s. & & all $p<0.05$ & all n.s. & \\
\hline
\end{tabular}

Conclusions: Manometry with non-perfused transducers in minimally prepared bowe demonstrated significant differential segmental colonic responses and propulsive patterns to food and cisapride.

\section{OXI/3 409}

SEROTONERGIC CONTROL OF POSTPRANDIAL COLONIC MOTIIITY. M. Camilleri, M.R. vor der Obe, J.S. Scolapio, R.B. Hanson, Gastroenterology Research Unit, Mayo Clinic, Rochester, MN, U.S.A.

The precise mechanisms resulting in the postprandial (PP) gastrocolonic motor response are unclear. A prominent cholinergic mechanism is suggested by the inhibition of both phasic and tonic PP colonic contractility by atropine. Myenteric cholinergic neurons are modulated by serotonin (5HI) through type 3 receptors. We wished to test the hropthesis that $5 \mathrm{HT}_{3}$ mechanisms modulate the PP gastrocolonic response in health. Our aims were to evaluate the effects of a $5 \mathrm{HT}_{3}$ antagonist, ondansetron, on proximal and distal colonic motility in bealthy subjects by two experimental protocols using a placebocontrolled, parallel-group design. Methods: Experiment I: In 10 healthy subjects with unprepared colon we scintigraphically measured ileal and ascending colon (AC) emptying and proximal AC (PAC) volume (with a standardized length of $A C$ assessed in each subject) during fasting and 2 .hours after a 1,000-kcal meal-(PP). We used-a-methacrylate-coated capsule containing ${ }^{111}$ In-Amberlite pellets which were released in the ileum, and calculated PAC volume by full-width, half-maximum analysis of planar images of the colon. Experiment II: We measured colonic pressure activity and tone of the prepared colon in 12 different healthy subjects. Motility was assessed by means of a combined barostat-manometry assembly placed in the distal transverse or upper descending colon with the aid of endoscopy. The-protocol of the study was similar to experiment $L$ Results: I. Fasting PAC volumes were similar in placebo and ondansetron groups and were unaltered by placebo or ondansetron. PAC volumes showed a biphasic PP response: an initial ( $0-25 \mathrm{~min})$ modest increase associated with ileal emptying, followed by contraction (30-105 $\mathrm{min}$ ) in the placebo group. This contraction was blocked by ondansetron. AC emptying was less with ondansetron $(9 \pm 4 \%$ in $2 \mathrm{hr}$ ) than placebo $(25 \pm 11 \%$ in $2 \mathrm{hr} ; \mathrm{p}=0.15)$. II. Ondansetron did not influence fasting colonic tone, but reduced the PP tonic and phasic gastrocolonic motor responses. Data show mean \pm SEM; statistics by paired or unpaired t-test as appropriate. " $p<0.05$ vs. placebo; * $p<0.05$ vs. $0.25 \mathrm{~min} P \mathrm{P} ; t p<0.05$ vs. fasting; motility index $=\ln \left(\sum\right.$ amplitudes $x$ no. of contractions +1$)$

\begin{tabular}{|c|c|c|c|c|c|c|}
\hline & $\frac{\text { olume }}{0-25}$ & $\frac{(\mathrm{ml})}{30-105}$ & $\begin{array}{r}\mathrm{TC} \\
\text { (barostat }\end{array}$ & $\begin{array}{l}\text { ne } \\
\text { vol, } \mathrm{ml})\end{array}$ & $\begin{array}{l}\text { Motili } \\
\text { (man }\end{array}$ & $y$ Index \\
\hline OA & $\min \mathrm{PP}$ & PP & Fasting & PP & Fasting & PP \\
\hline $60 \pm 1$ & $\begin{array}{l}64 \pm 6 \\
56 \pm 6\end{array}$ & $69 \pm 7^{*}$ & $\begin{array}{l}248 \pm 32 \\
222+28\end{array}$ & $\begin{array}{l}227 \pm 32 \\
169+22\end{array}$ & $\overline{9.1 \pm 1.0}$ & \\
\hline
\end{tabular}

$60 \pm 13 \quad 64 \pm 6 \quad 69 \pm 7 * 240 \pm 32 \quad 227 \pm 32 \quad 9.1 \pm 1.0 \quad 10.6 \pm 0.4$ Conclusion: In health, proximal and distal colonic motor functions are stimulated postprandially and are modulated by $\mathrm{SHT}_{3}$ mechanisms.
TOTAL AND SEGMENTAL COLONIC TRANSIT IN CELIAC DISEASE (CD) - J.C. Bai, C. Martinez, E. Mauriño, L. soerr, M. Vazquez. Gastroenterology Mospital. Buenos Aires. Argentina. Diarrhea is the most common complaint of patients with untreated celliac disease $(C D)$. Up to now, the pathophysiology of dierrhea has been attributed primarily to morphological and absorptive disturbances of small bovel function. However, abnormal colonic transit may also contribute to the diarrhea of $\boldsymbol{C D}$. Aims: To determine whether $\infty$ alters gut transit and whether improvement in the elinical status of $\infty$ influence colonic transit. Methods: We studied 3 groups: 1) 26 patients with untreated $\omega_{0}$; 2) 14 Co potients successfully treated with gluten-free diet for - mean of 4.3 yr. (range 6 mo$16 \mathrm{yr}$ ); and 3) 15 healthy controls. Patients and controls were all femoles, matched for age. All participants underwent measurements of: a) oro-cecal transit by the lactulose breath H2 Test and b) total and segmental colonic transit time by a simplifiech radiological test (Gastroenterology 1987;82:407). Results $\left(X_{ \pm}+S E M\right)$ : Untreated $C D$ patients had a significantly delayed orocecal transit time $(121 \pm 19$ min) compored to treated patients $(76 \pm 10$ min; p<0.01 -ANOVA with "Bonferroni correction-) and controls (80+9 min; p<0.001). Ho differences were observed as to thether or not fat malabsorption was present. Overall colonic transit uas significantly faster in intreated $(25.4+2.8 \mathrm{hs})$ than in treated $C D$ patients $(40.1+4.5 \mathrm{hs} ; \mathrm{p}<0.05)$ and controls $(37.5 \pm 4.5 \mathrm{hs} ; \mathrm{p}<0.05)$. Patients with steatorrhea $(>7 \mathrm{~g} / \mathrm{day})$ had a significant faster transit $(24.3+3.4 \mathrm{hs})$ than did patients with normal fecal fat $(37.8 \pm 4.8 \mathrm{hs}$; p<0.05); however, a weak imverse correlation was observed between both factors (Spearman's test $r:-0.38 ; p<0.05$ ). Mean transit time for patients with diarrhea (stool wight $>200 \mathrm{~g} /$ day; $21.3 \pm 3.4$ hs) was faster than that for patients without diarrhea $(41.3+3.8 \mathrm{hs} ;$ p<0.001). A significant inverse correlation between both parameters was observed ( $r:-0.55$, p<0.001). The greacest change in segmental colonic transit was observed in the rectosigmoid segment of untreated CD patients $(9.0 \pm 1.8 \mathrm{hs})$ compered with controls (18.6\$2.9 hs; p<0.05). No evidences of right colon accommoctation was observed since transit time through this segment was similar for the different groups. In conclusion, oro-cecal transit was delayed in 10 petients whatever was the grade of fecal fat excretion. Accelerated colonic transit contributes to the pathophysiologr of chronic dierrhea in 0 . Ho evidences of

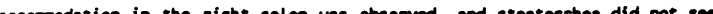
accommodation in the right colon wast
THE ACTION OF NICOTINE AND ITS METABOLITE, COTININE ON THE DISTAL HUMAN COLON. LS.Jameson. J.Rogers, A.H.Raimundo, C.Feyerabend, M.M.Henry, J.J.Misiewicz. Dept Gastroenterology, Central Middlesex Hospital, Acton Lane, London NW10 TNS.

Smoking may be involved in the aetiology of ulcerative colitis and abnormal colonic motility has been described in this condition. Anecdotally an early moming cigarette can induce the desire to defaecate. The effect of nicotine on the distal human colon has not been investigated.

To determine the effect of nicotine on distal colonic motility 16 healthy volunteers (4F, mean age $26.4 \mathrm{y}$ ) were studied. In addition, 11 of the subjects agreed to undergo a second study. In a random, single blind manner, the subjects chewed $4 \mathrm{mg}$ of nicotine gum or placebo gum. Colonic pressure activity was measured using 2 water perfused tube assembly placed in the sigmoid colon with a flexible sigmoidoscope in the unprepared.bowel without sedation. After a $30 \mathrm{~min}$ baseline the active or placebo gum was chewed for $30 \mathrm{~min}$ and recordings continued for a further $90 \mathrm{~min}$. Plasma nicotine and cotinine levels were measured prior to, at $15 \mathrm{~min}$, and then at $30 \mathrm{~min}$ intervals after starting chewing.

Chewing either active or placebo gum rapidly increased colonic pressure activity as measured by the colonic activity index (area under the curve) for the study segment as a whole. [707 $\mathrm{mmHg} \cdot \mathrm{min}(147)$, mean(SEM) active gum and 730(109), placebo vs 536(76), baseline for the active gum and 628(109) baseline for the placebo]. This was followed by a decrease in pressure activity in both groups but which was more marked the active group [371(58) vs 536(76), baseline, $P=0.04$ ) than in the placebo group, [513(86) vs 628(109), baseline, $P=0.3$ ]. With the active gum plasma nicotine levels peaked $15 \mathrm{~min}$ after starting chewing $[10.2(1.4) \mathrm{ng} / 1$, mean(SEM) vs $0.22(0.07)$, baseline, $P$ $\leq 0.001]$ and the decrease in colonic pressure activity occurred temporally related to a rising cotinine level. Peak cotinine levels were $14.7(3.8) \mathrm{ng} / \mathrm{l}$ ys $2.5(1.0)$, baseline, $P \leq 0.001$, occurring $90 \mathrm{~min}$ after starting chewing.

Nicotine, probably acting through its metabolite, cotinine, profoundly affects distal human colonic motility. Further studies to assess the action of nicotine on the colon in ulcerative colitis are warranted. 
INTENSITY OF THE INTESTINAL MIGRATING MOTOR COMPLEX (MMC) PREDICTS COLONIZATION WITH GRAM NEGATIVE BACILLI IN PROXIMAL SMALL INTESTINE. E. Husebye, V. Skar, T. Høverstad, T. Iversen, K. Melby. Depts. of Medicine and Microbiology, Ulleval University Hospital, and Dept. of Gynecologic Oncology, The Norwegian Radium Hospital.

The significance of impaired fasting motility of small intestine in the pathophysiology of bacterial overgrowth was suggested by the pioneer study of Vantrappen et al (J Clin Invest 1977). Their findings, however, have not been confirmed, and the relationship between MMC and microbial flora of the proximal small intestine remains to be settled.

The present prospective study of forty-one female patients with symptoms of late radiation enteropathy (LRE) adresses this issue. All patients had been subjected to previous abdominal radiotherapy for gynecological cancer, and age was mean 61 years (range 41-81). Intestinal motility was recorded by prolonged ambulant manometry (Husebye et al, Dig Dis Sci 90), and microbial culture and markers of microbial metabolism were applied to elucidate intestinal microecology. Definitions of normal motility patterns were based on findings in 27 healthy controls.

Significant growth of Gram negative bacilli in duodenum was found in 11 of 41 patients $(27 \%)$. The intensity of MMC, expressed by cumulated calculated length of MMC, explained $61 \%$ and $71 \%$ of the variability in Gram negative growth in the stomach $(p<0.001)$ and duodenum $(p<0.001)$, respectively (linear regression). Absence of MMC or reduced frequency and slow migration along the intestine were the main features of abnormal MMC activity. After stratification with respect to Gram negative colonization, the appearence of phase III of MMC after a liquid-solid meal of $1700 \mathrm{KJ}$ was significantly later for the group with Gram negative bacilli in duodenum ( $p<0.001$, Mantel-Haenszel log-rank test). High concentrations of bacterial species belonging to the upper respiratory tract flora were found regardless of MMC activity.

Fasting motility of the proximal small intestine seems to be the main line of defense against colonization with Gram negative bacilli in the upper GI tract, and prolonged ambulatory manometry is suitable for detecting abnormalities of pathophysiological relevance. Investigations of intestinal motility and microflora are useful tools in the diagnostic workup of patients with symptoms of LRE, that should be utilized in the clinical management.
THE EFFECT OF AGE, SEX AND PARTTY ON ANORECTAL FUNCTION: A PROSPECTIVE STUDY IN HEALTHY VOLUNTEERS. I.S.Jameson, Y.W. Chia, M. A.Kamm, C.T.M.Speakman. M.M.Henry, Dept of Gastroenterology, Central Middlesex Hospital and St. Mark's Hospital.

This study aimed to prospectively determine, in healthy volunteers, the effect of age, sex and parity on anorectal function.

Methods: 91 healthy subjects were studied ( $51 \mathrm{~F}$, mean age $40 \mathrm{y}$, [2, SEM], $40 \mathrm{M} 52$ y [3]). Maximum resting pressure (RP) -and maximum squeeze pressure (MSP) were measured using a microballoon method. Rectal sensation to distension, and rectal (RS) and mid anal electrosensitvity (AS) were measured. Perineal descent, pudendal nerve latencies (PNTML) and fibre density (FD) of the EAS were also measured. The group as a whole was analysed using analysis of covariance of all-the parameters by sex controlled for age, and using linear regression analysis for the effects of age. The women were analysed separately using analysis of covariance by parity, controlled for age.

Results: Sex was an independent variable for MSP $\left(148 \mathrm{cmH}_{2} \mathrm{O}\right.$, mean [9, SEM] of $\mathrm{cf} 95[7]$ \&,P<0.001); the degree of perineal descent $(1.0[0.1]$ o cf 1.3cm[0.1] \&, P=0.02); FD (1.43[0.03] to cf 1.52(0.03) \&, P=0.021) while age was an independent variable for $R P(R=-0.43, P=0.0001)$; perineal position $(R=-0.55, P \leq 0.0001) ; A S(R=0.42, P=0.0001)$ and $R S$ $(R=0.54, P \leq 0.0001)$. Within the women parity was an independant variable for MSP (105[13] $\mathrm{cmH}_{2} \mathrm{O}$ in nullips cf 75[6] in multips, $\left.\mathrm{P}=0.04\right)$ and AS $(5.3[0.5] \mathrm{mA}$ cf $4.5[0.6], P=0.02)$. PNTML's increased with age in both the group as a whole $(R=0.53, P \leq 0.0001)$ and in women alone irrespective of parity $(P \leq 0.0001)$.

Conclusion: Increasing age leads to perineal descent, slowed pudendal nerve conduction, a fall in resting anal pressure, and decreased anorectal sensory function. Women have a lower anal squeeze pressure, more perineal descent and a greater muscle fibre density than men. Parity leads to lower squeeze pressures but no other major change in anorectal function. COMPETENT ANAL SPHINCTERS IN FAECAL
INCONTINENCE?

\section{Maria Papachrysostomou, AN Smith}

University of Edinburgh, Western General Hospital, Edinburgh EH4 2XU, UK

Two-hundred and seventy-seven patients with faecal incontinence (FI) had anorectal studies. Twenty-two patients (median age 56 years) appeared to have competent anal sphincters on manometric testing. These patients complained of FI for 36 months $(95 \% \mathrm{CI} ; 7,14)$ and reported a frequency of defaecation of 7 occasions per week (95\% CI; 7,14$)$.

The manometry tests-showed the maximum resting pressure (MRP) in the anal canal as $140 \mathrm{cmH}_{2} \mathrm{O}$ (control group: 120 $\mathrm{cmH}_{2} \mathrm{O} ; \mathrm{p}>0.05$ ), the increment in the anal canal pressure on coughing (CP) as $130 \mathrm{cmH}_{2} \mathrm{O}$ (controls: $90 \mathrm{cmH}_{2} \mathrm{O} ; \mathrm{p}>0.05$ ) and the voluntary contraction on 'squeezing' (SQP) as $150 \mathrm{cmH} \mathrm{H}_{2}$ (controls: $150 \mathrm{cmH} 2 \mathrm{O} ; \mathrm{p}>0.05$ ). The proctometrogram showed the rectal sensory threshold (RST) as $113 \mathrm{ml}$ (controls: $80 \mathrm{ml}$; $\mathrm{p}>0.05$ ), the maximum rectal capacity (MRC) as $350 \mathrm{ml}$ (controls: 420 ml; $p>0.05$ ), whereas the rectal compliance $(R C)$ was 4 $\mathrm{ml} / \mathrm{cmH}{ }_{2} \mathrm{O}$ (controls: $7.4 ; \mathrm{p}<0.02$ ). The electrophysiological tests showed the pudendo-anal reflex latency (PARL) as $38.4 \mathrm{~ms}$ (controls: $39.4 ; p>0.05$ ).

These results eliminate the possibility of FI due to failure of sphincter control. There was neither a RST deficit nor a reduced MRC. The PARL was normal indicating a maintained integrity of conduction through the conus medullaris. The reduced RC conduction through the conus medullaris. The reduced RC
observed in association with normal MRC implies higher observed in association with normal MRC implies higher
intrarectal pressures. A reduced RC has been previously intrarectal pressures. A reduced RC has been previously
described in the irritable bowel syndrome. High intrarectal pressures might overcome the anal canal barrier pressure during phases of spontaneous relaxation, such as occur in the 'sampling reflex'.

In conclusion, patients may suffer from faecal incontinence in the presence of competent anal sphincters. The control of continence is multifactorial and may equally depend on rectal function and motility as well as competent anal sphincter muscles.
AMBULANT ANORECTAL MANOMETRY: A NEW DIAGNOSTIC TOOL FOR THE INVESTIGATION OF SLOW TRANST CONSTIPATION. LلJ.A. Auwerda and W.R. Schouten, Department of General Surgery, University Hospital Dijkzigt, Rotterdam, The Netherlands.

Ambulant Anorectal Manometry (AAM) enables the simultaneous recording of anal and rectal pressure fluctuations over a prolonged period of time, and under physiological conditions. Aim of our study was to investigate the value of this new technique in the evaluation of Slow Transit Constipation (STC). Using a fully ambulatory system (MMS-systems), AAM was performed in 10 healthy volunteers ( $M: F=5: 5$, mean age 32-yrs, range 22-51), and 7 female STC-patients (mean age $42-y r s$, range 17-76). A total of 400-hrs (23.5-hrs/subject) of recording was obtained. Although anal as well as rectal pressure showed a remarkable drop during sleep, the ano-rectal pressure gradient remained intact in-all controls-and in 5_STC=pts. Prolonged rectal pressure measurement revealed characteristic runs of pressure fluctuations with high amplitude $(>10 \mathrm{mmHg})$. These Rectal Motor Complexes (RMC's) were seen in all controls (mean number per 24-hrs: 12.5) with a mean frequency of $0.5 / \mathrm{hr}$ (range $0.2-0.8$ ) and a mean duration of 6.6 minutes (range: 4.3-12.4). In contrast no RMC's were observed in 2 STC-pts, whereas the others showed significant fewer RMC's (mean number per 24-hrs: 7.3 , mean freq $0.3 / \mathrm{hr}$, range $0.1-0.4$, $P<0.05$, Mann-Whitney).

We conclude that the difference in RMC's between controls and STC-pts demonstrates that AAM can provide a diagnostic criterium and is therefore a usefull tool in the investigation of slow transit constipation. 